Cite this: RSC Adv., 2016, 6, 24060

Received 21st January 2016

Accepted 25th February 2016

DOI: $10.1039 / c 6 r a 01839 d$

www.rsc.org/advances

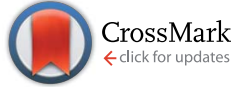

\section{Confocal depth-resolved micro-X-ray absorption spectroscopy study of chemically strengthened boroaluminosilicate glasses}

\author{
Pieter Tack, ${ }^{\text {*a }}$ Stephen Bauters, ${ }^{\text {ab }}$ John C. Mauro, ${ }^{c}$ Morten M. Smedskjaer, ${ }^{d}$ \\ Bart Vekemans, ${ }^{a}$ Dipanjan Banerjee, ${ }^{b}$ Wim Bras $^{e}$ and Laszlo Vincze ${ }^{a}$
}

\begin{abstract}
It is crucial to understand the structural origins of macroscopic properties in silicate glasses for their hightech applications. An example of such an application is chemically strengthened boroaluminosilicate glasses that are exposed to an ion exchange process during which alkali ions (e.g. $\mathrm{Na}^{+}$) are replaced by larger (e.g. $\mathrm{K}^{+}$) ions. Despite the empirically thorough understanding of this exchange process, much less is known about the fundamental physics of the process. Since Fe atoms are a suitable probe for monitoring chemical stress-induced changes in the local structure in the chemically strengthened glasses, a set of chemically strengthened boroaluminosilicate glasses containing $1 \mathrm{~mol} \% \mathrm{Fe}_{2} \mathrm{O}_{3}$ are here studied using depth-resolved confocal X-ray absorption near-edge structure (XANES) and extended Xray absorption fine structure (EXAFS) spectroscopy. Information on the Fe oxidation state, coordination number, and bond distance as a function of the sample depth and glass composition is obtained. These new insights on chemical stress-induced changes will aid in the further development and improvement of such damage-resistant glasses.
\end{abstract}

\section{Introduction}

Understanding the structural origins of macroscopic properties in silicate glasses is crucial for their high-tech applications. The properties of glasses not only depend on the chemical composition, but also on the processing history. Thermal, pressure and chemical treatments can influence the macroscopic material properties to a large degree. For example, it is known that the coordination number $(\mathrm{CN})$ of atoms or ions in materials increases through application of a sufficiently high pressure, ${ }^{\mathbf{1 - 4}}$ a phenomenon that also applies to glassy materials. ${ }^{5-8}$ These modifications due to processing conditions are not necessarily uniform throughout the material, as part of the manufacturing process might be to induce depth dependent modifications. An example of this is the ion exchange process (IX), widely used in the glass industry.

In this process, the to be processed glass object is placed in a molten inorganic salt bath $\left(\right.$ e.g. $\left.\mathrm{KNO}_{3}\right)$ at elevated temperatures whereupon smaller alkali ions $\left(e . g . \mathrm{Na}^{+}\right)$from the glass are

\footnotetext{
a Department of Analytical Chemistry, Ghent University, Krijgslaan 281 S12, 9000 Ghent, Belgium. E-mail: pieter.tack@ugent.be

${ }^{b}$ Dutch-Belgian Beamline (DUBBLE), The European Synchrotron Radiation Facility (ESRF), 38043 Grenoble Cedex 9, France

'Science and Technology Division, Corning Incorporated, Corning, NY 14831, USA ${ }^{d}$ Department of Chemistry and Bioscience, Aalborg University, 9220 Aalborg, Denmark ${ }^{e}$ Netherlands Organisation for Scientific Research (NWO), The European Synchrotron (ESRF), 38043 Grenoble Cedex 9, France
}

replaced by larger ones $\left(\right.$ e.g. $\left.\mathrm{K}^{+}\right)$from the molten salt bath. As a result, the outer layers of the glass have a different proportion of $\mathrm{K}_{2} \mathrm{O}$ and $\mathrm{Na}_{2} \mathrm{O}$ while the core of the material remains unchanged.

This exchange leads to formation of a compressive stress layer near the surface of the glass; it is well known and widely used by industry for production of chemically strengthened scratch and damage resistant glasses. ${ }^{\mathbf{9}, 10}$ As electronics devices are more and more portable, consumer demand dictates the devices not only having a physically pleasing appearance and functionality but also having excellent mechanical properties, including damage and scratch resistant surfaces. Some of the most successful examples are smartphones and tablets with cover glass post-treated by the IX process. The resulting high compressive stress of the material is the basis of the excellent mechanical properties of cover glasses.

Although the ion exchange process is empirically reasonably well understood, ${ }^{9,10}$ much less is known about the fundamental physics of the process. For instance, it is not known which chemical state the dopant elements are in as a function of diffusion depth in alkali-aluminosilicate glasses. According to molecular dynamics simulations of ion-exchanged glass, the CN of network formers is unchanged due to the IX process, whereas the invading alkali ions possess unique structures unattainable via standard melt-quenching processes. ${ }^{\mathbf{1 1 - 1 3}}$ However, this has not yet been confirmed experimentally.

In this study, a set of boroaluminosilicate glasses, containing $1 \mathrm{~mol} \%$ of $\mathrm{Fe}_{2} \mathrm{O}_{3}$ as dopant material, with varying $\mathrm{SiO}_{2}$ and 
$\mathrm{Al}_{2} \mathrm{O}_{3}$ concentrations are provided by Corning Inc. (NY, USA). ${ }^{\mathbf{1 4}}$ Fe atoms are used here as a suitable probe for monitoring chemical stress-induced changes in $\mathrm{CN}$, oxidation state, and bond distances in the glasses. ${ }^{15}$ Previous studies reported on the changes in $\mathrm{CN}$ of $\mathrm{B}, \mathrm{Al}$ and the presence of non-bridging oxygen (NBO) in these glasses as a result of the different $\mathrm{SiO}_{2} / \mathrm{Al}_{2} \mathrm{O}_{3}$ ratios. ${ }^{16-19}$

Here we used depth-resolved X-ray absorption spectroscopy (XAS) to determine the chemical state and $\mathrm{CN}$ of $\mathrm{Fe}$ in the glasses. To monitor depth resolved differences in Fe state in the top $50 \mu \mathrm{m}$ of the glass and in the bulk ( $100 \mu \mathrm{m}$ depth), i.e., in compressive and tensile stress regions, respectively, polycapillary optics based confocal XAS measurements are performed, applying a rarely achieved $10 \times 10 \times 15 \mu^{3}$ spatial resolution. The $\mathrm{Fe}-\mathrm{K}$ X-ray absorption near-edge structure (XANES) spectroscopy pre-edge peak contains information on both the oxidation state and $\mathrm{CN}$ of the absorbing atom. ${ }^{\mathbf{2 0}-26}$

Conventionally, information on the $\mathrm{CN}$ and local structure of the absorbing atom is obtained through extended X-ray absorption fine structure (EXAFS) spectroscopy experiments. Here, we opt not to perform EXAFS measurements for each sample at each depth due to the inherently longer acquisition time compared to XANES experiments (easily a factor 10 difference). Instead, EXAFS experiments are performed on a few selected samples at a depth near the surface (25 $\mu \mathrm{m}$ depth) and closer to the bulk (55 $\mathrm{m}$ depth). This is done in order to compare with the XANES results and verify that the conclusions based upon the XANES results are valid even beyond the structural length scale for which XANES normally would render results.

A major objective of this approach is to minimize the local absorbed radiation dose since it has become clear in recent years that when glassy material is exposed to a too high local Xray dose, the structural and chemical information obtained via X-ray based techniques might be compromised due to the generation of a high local concentration of photoelectrons. ${ }^{27-30}$ The radiation dose required to obtain valid XANES results is only a fraction from the dose required to obtain a complete EXAFS spectrum and therefore an assessment is made if the information rendered by XANES is sufficient or if complete EXAFS scans have to be made.

\section{Experimental}

\section{Glass samples}

A series of 10 boroaluminosilicate glass samples with varying $\mathrm{SiO}_{2}$ and $\mathrm{Al}_{2} \mathrm{O}_{3}$ concentration (see Table 1) and each containing approximately $1 \mathrm{~mol} \% \mathrm{Fe}_{2} \mathrm{O}_{3}$ were prepared by melt-quenching, as described in detail elsewhere. ${ }^{17}$ The glasses will be further referred to by their code as shown in the top row of Table 1. To induce a high compressive stress in the surface layers of the glasses, each glass sample was cut to a size of $2 \times 2 \times 0.1 \mathrm{~cm}^{3}$ and ion exchanged in a refined grade $\mathrm{KNO}_{3}$ molten salt bath for 4 hours at $410{ }^{\circ} \mathrm{C}$. During this ion exchange process, $\mathrm{Na}^{+}$ions are replaced by the larger $\mathrm{K}^{+}$ions, generating a compressive stress in the glass surface, thereby improving its mechanical durability. Due to the nature of the diffusion-limited ion
Table 1 Glass composition in mol\% before applying the ion exchange process

\begin{tabular}{lrrrrrrrrrr}
\hline & Al0 & Al1 & Al2.5 & Al5 & Al7.5 & Al10 & Al12.5 & Al15 & Al17.5 & Al20 \\
\hline $\mathrm{SiO}_{2}$ & 79.4 & 78.9 & 77.4 & 74.7 & 71.8 & 68.9 & 67.1 & 64.1 & 62.3 & 61.1 \\
$\mathrm{Al}_{2} \mathrm{O}_{3}$ & 0.3 & 0.7 & 2.2 & 4.7 & 7.6 & 10.3 & 12.6 & 15.6 & 17.9 & 19.4 \\
$\mathrm{Na}_{2} \mathrm{O}$ & 14.6 & 14.5 & 14.6 & 14.6 & 14.7 & 14.8 & 14.3 & 14.3 & 13.7 & 13.6 \\
$\mathrm{~B}_{2} \mathrm{O}_{3}$ & 4.9 & 4.9 & 4.9 & 5.0 & 4.9 & 5.0 & 5.0 & 5.0 & 5.1 & 5.0 \\
$\mathrm{Fe}_{2} \mathrm{O}_{3}$ & 0.9 & 0.9 & 0.9 & 1.0 & 1.0 & 1.0 & 1.0 & 1.0 & 0.9 & 0.9
\end{tabular}

exchange process, more $\mathrm{Na}^{+}$ions are replaced at the surface of the glass compared to the bulk of the glass.

\section{XAS}

Confocal XAS experiments were performed at BM26A, part of the Dutch-Belgian beam line (DUBBLE) at the ESRF. ${ }^{31}$ The beam line receives the radiation from a $0.40 \mathrm{~T}$ ESRF bending magnet. A double crystal $\mathrm{Si}(111)$ monochromator operating in a fixedexit mode in combination with a collimating mirror allows an energy resolution $\Delta E / E$ of $\sim 1.7 \times 10^{-4}$ at $9.659 \mathrm{keV}$. A vertically focusing mirror behind the monochromator allows vertical focusing and higher energy harmonic suppression.

The primary intensity was determined with a gas-filled ion chamber and the transmitted intensity was determined with an identical device. The gas mixtures in both ionization chambers were adjusted to allow approximately $10 \%$ absorption in the first and about $70 \%$ absorption in the second ionization chamber at $7.212 \mathrm{keV}$. The photon flux was $\sim 6 \times 10^{9}$ photons per $\mathrm{s}$ at the sample position at the Fe K-edge energy (7112 eV). A $4 \mu \mathrm{m}$ thick pure iron foil (Goodfellow SARL, Lille, France) was measured in transmission mode at regular time intervals during the experiment to correct for monochromator energy shifts by setting the first inflection point of the XANES profile to $7112 \mathrm{eV}$.

The incident X-ray beam was focused down to a $10(\mathrm{~V}) \times$ $10(\mathrm{H}) \mu \mathrm{m}^{2}$ (FWHM) spot size at the sample position at the $\mathrm{Fe}-\mathrm{K}$ edge energy using a polycapillary X-ray lens (XOS, NY, USA). A Vortex-EM silicon drift detector (Hitachi High-Technologies Science America Inc., California, USA), equipped with a collimating polycapillary optic lens (XOS, NY, USA), was placed perpendicular to the incident X-ray beam in the plane of polarization. The foci of both polycapillaries were aligned to coincide, thus obtaining a confocal detection scheme in which information can be selectively obtained from a $10(\mathrm{~V}) \times 10(\mathrm{H}) \times$ 15(D) $\mu \mathrm{m}^{3}$ volume inside the sample matrix at the Fe-K edge energy. By scanning the sample through this confocal volume, direct 3D spatially resolved sample data can be collected. ${ }^{32-34} \mathrm{~A}$ schematic of the setup is shown in Fig. 1.

Depth resolved XANES scans were acquired in $5 \mu \mathrm{m}$ steps for the first $50 \mu \mathrm{m}$ of the glass surface, and an additional XANES scan was performed at a depth of $105 \mu \mathrm{m}$, representative for the bulk of the glasses. The reported depths correspond to the maximal depth probed by the confocal volume, e.g. a reported depth of $20 \mu \mathrm{m}$ corresponds to the volume 5-20 $\mu \mathrm{m}$. A single XANES scan was split up in energy as follows: from $7012.0 \mathrm{eV}$ to 


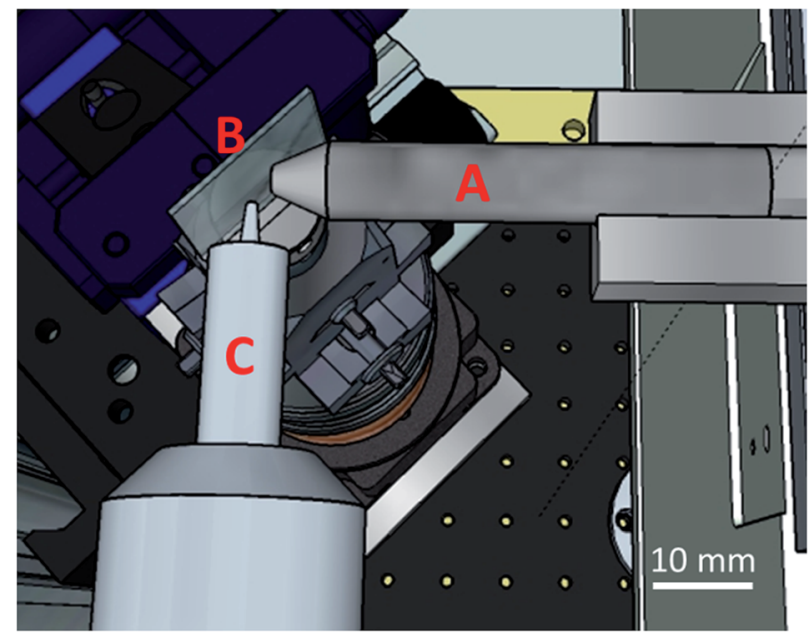

Fig. 1 Schematic overview of the confocal micro-XAS setup at BM26A. Displayed are the focusing optic (A), focusing the primary beam on the sample (B), mounted on a goniometer head. The focus of confocal optic (C) mounted on the SDD detector coincides with that of the focusing optic, thus creating a confocal volume from which information is selectively acquired.

$7092.0 \mathrm{eV}$ in $3.8 \mathrm{eV}$ steps, from $7093.0 \mathrm{eV}$ to $7110.0 \mathrm{eV}$ in $0.9 \mathrm{eV}$ steps, from $7110.5 \mathrm{eV}$ to $7120.5 \mathrm{eV}$ in $0.5 \mathrm{eV}$ steps, from 7121.0 $\mathrm{eV}$ to $7132.0 \mathrm{eV}$ in $0.9 \mathrm{eV}$ steps and from $7133.0 \mathrm{eV}$ to $7343.0 \mathrm{eV}$ in $3.0 \mathrm{eV}$ steps. The total integration time per energy step was adjusted for each depth and sample based on a visual inspection of the obtained XANES spectrum.

Raw XANES data were normalized for incident beam flux using the primary ionization chamber signal, pre-edge subtracted using a linear function and post-edge normalized at an energy of $E_{0}+50 \mathrm{eV}$. Additionally, the slow variations caused by the atomic absorption profile before and after the edge were subtracted to facilitate linear combination analysis spectra comparisons. ${ }^{35}$ Due to the high absorbing nature of the glass matrix and the intrinsic properties of the confocal detection method, no self-absorption effects are expected and thus were not corrected for. To obtain data on the Fe oxidation state and coordination number $(\mathrm{CN})$, the pre-edge peak, originating from the $1 \mathrm{~s} \rightarrow 3 \mathrm{~d}$ electron transition, was fitted using a Gaussian function on top of an arctangent background, in line with previous research performed by Wilke et al., ${ }^{21}$ Giuli et al. ${ }^{22}$ and others. ${ }^{20,23-26}$

EXAFS data were acquired at a depth of $25 \mu \mathrm{m}$ and $55 \mu \mathrm{m}$ in the glass, up to $11 \AA^{-1}$ in $k$-space using $0.05 \AA^{-1}$ steps. The data was processed using the VIPER software package ${ }^{36}$ and fitted using FEFF7 (ref. 37 and 38) calculated scatter paths. A spline was fitted using the VIPER "through the knots" routine, applying 7 knots spaced evenly over the Fourier transformed $k$ range from 3 to $10.5 \AA^{-1}$. The first coordination shell was fitted in $R$-space, fitting the module and imaginary space from 0.7 to $2.0 \AA$ (before phase shift correction). During the fitting process, an amplitude reduction factor $S_{0}{ }^{2}$ equal to 0.43 was used, as determined by fitting a hematite structure to have $6 \mathrm{O}$ neighboring atoms (N) around the absorbing Fe atom. Due to the strong correlation between $\mathrm{N}$ and ${S_{0}}^{2}$, the Debye-Waller-like factors were constrained between 0.0025 and $0.0035 \AA^{2}$.

\section{Results and discussion}

XANES profiles for the Al10 glass, after IX had been performed, at various depths are displayed in Fig. 2. No clear difference is visible in general between the curves, aside from the different degrees of noise. The curves corresponding to points deeper inside the glass matrix show poorer signal to noise ratios as a result of the decreased intensity measured at these points, which in turn is due to increased absorption related to the larger X-ray path length in the sample. Similar XANES curves are found for each of the ion-exchanged boroaluminosilicate glasses (not shown). When monitoring the Fe-K XANES preedge peak (Fig. 2 inset), subtle differences between the curves are visible. The results of the pre-edge peak surface area and position as a function of depth are shown in Fig. 3.

A change in pre-edge peak position as a function of $\mathrm{Al}_{2} \mathrm{O}_{3}$ content is observed (Fig. 3, right image): an increase in $\left[\mathrm{Al}_{2} \mathrm{O}_{3}\right]$ / $\left[\mathrm{SiO}_{2}\right]$ ratio corresponds to a decrease in pre-edge peak position. Additionally, a slight decrease in pre-edge peak position with increasing sample depth can be seen, which is discussed in more detail below. No clear trend with pre-edge peak integrated area and glass composition or depth is observed in Fig. 3, although it appears the pre-edge peak integrated area is slightly larger in the bulk compared to the surface. This as well is discussed in greater detail below.

Since the pre-edge peak position is related to the oxidation state of Fe in the sample,$^{\mathbf{2 0 - 2 6}}$ a comparison of the pre-edge peak position values obtained from known structures (not displayed) shows the Fe oxidation in the glasses, which is between $3+$ and $2+$. A gradual decrease in oxidation state with increased $\left[\mathrm{Al}_{2} \mathrm{O}_{3}\right]$ / $\left[\mathrm{SiO}_{2}\right]$ molar concentration ratio is observed, but an exact quantification of the $\mathrm{Fe}^{3+} / \mathrm{Fe}^{2+}$ ratio is not performed in this case as an insufficient amount of reference compounds with known $\mathrm{Fe}^{3+} / \mathrm{Fe}^{2+}$ ratio were available. An attempt was made to compare using database extracted reference spectra. However,

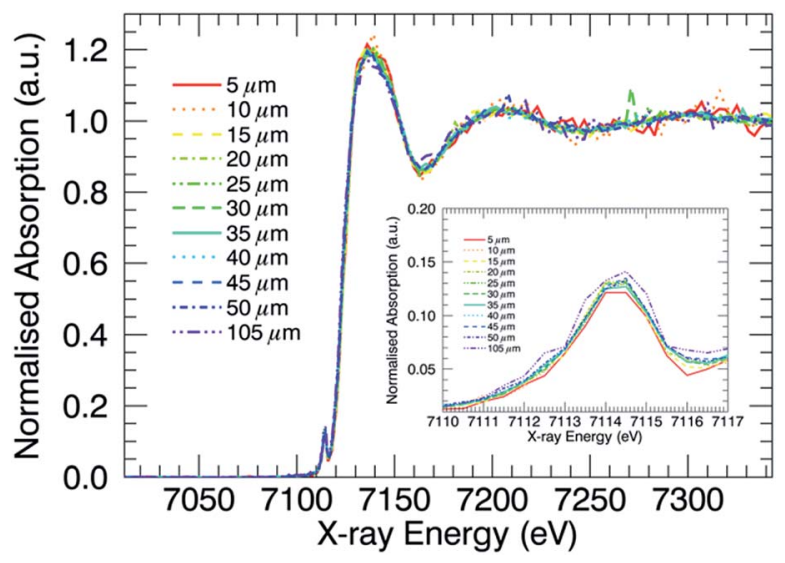

Fig. 2 Al10 Fe-KXANES profiles as a function of probed sample depth with magnification of the pre-edge peak region in the inset, containing information on the Fe oxidation state and coordination number. 

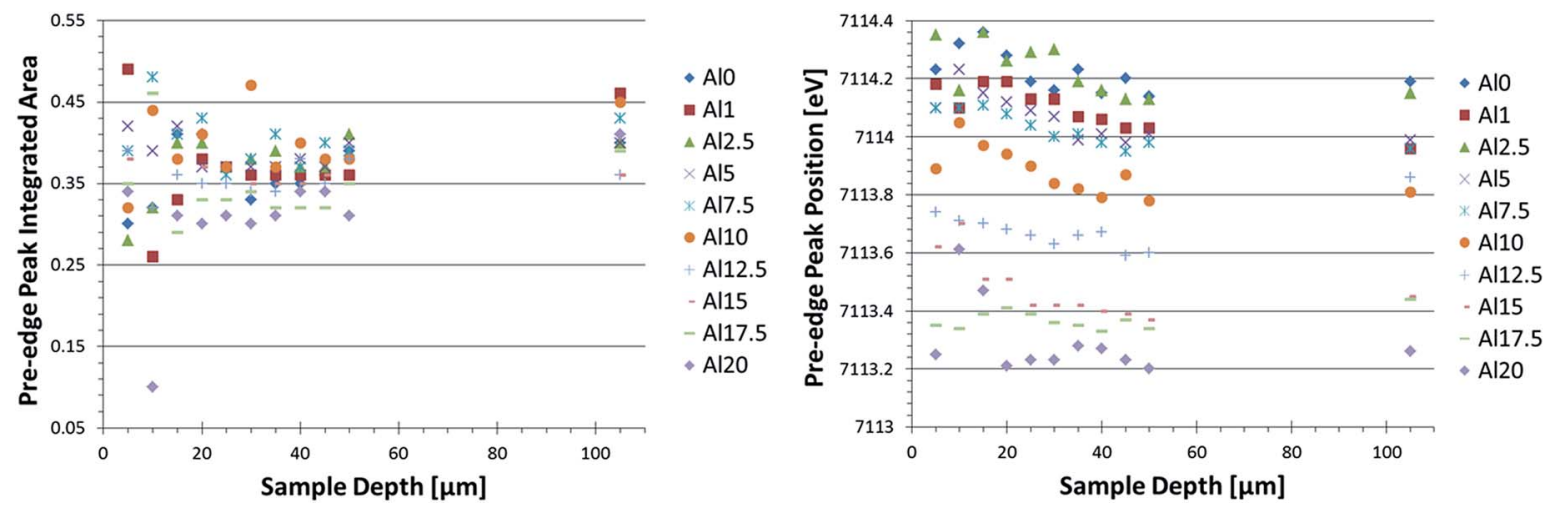

Fig. 3 Pre-edge peak integrated area (left) and position (right) as a function of sample depth and glass composition. An increase in pre-edge peak integrated area corresponds to a decrease in coordination number; an increase in pre-edge peak position relates to an increase in oxidation state.

a large uncertainty in the results arose due to the difference in energy resolution and step size applied during the scans acquired from the databases.

When comparing the average pre-edge peak area and position for the surface $(0-50 \mu \mathrm{m})$ with those in the bulk $(105 \mu \mathrm{m})$, a more clear change in $\mathrm{CN}$ and oxidation state of Fe as a function of depth in the glasses is found, as shown in Fig. 4. We note that this is the average $\mathrm{CN}$ for both $\mathrm{Fe}^{2+}$ and $\mathrm{Fe}^{3+}$ states since it is not possible to differentiate between these two contributions using XAS. Again, the trend in oxidation state (pre-edge peak position) as a function of glass composition is clearly visible. Additionally, the bulk is generally characterized by an increased pre-edge peak area and slightly decreased pre-edge peak position, respectively, indicating a lower $\mathrm{CN}$ and a slightly lower oxidation state for $\mathrm{Fe}$ atoms in the bulk as compared to the surface.
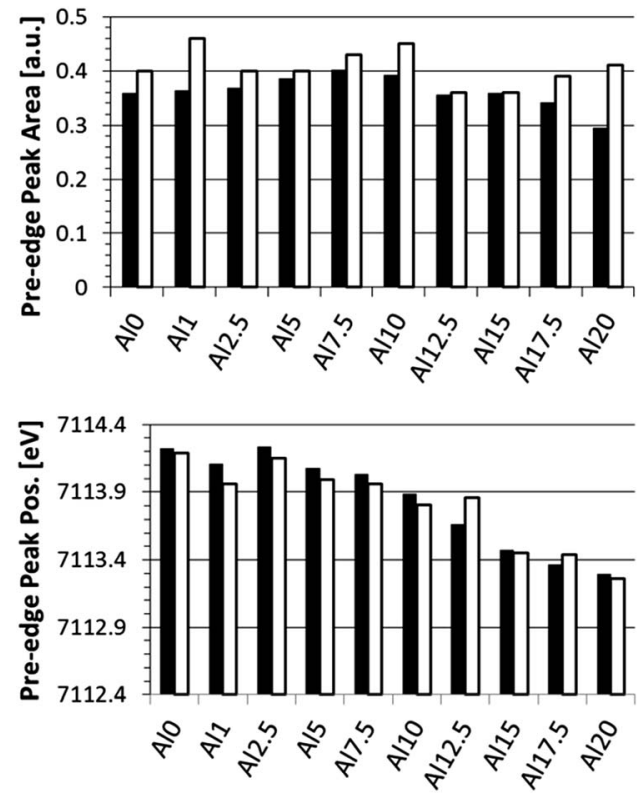

Fig. 4 Pre-edge peak integrated area (top) and position (bottom) for the averaged surface $(0-50 \mu \mathrm{m} ;$ black) and bulk (105 $\mu \mathrm{m}$; white) regions.
In order to obtain more quantitative information on the $\mathrm{CN}$ of Fe in the glasses, EXAFS experiments were performed in Alo, Al10, and Al20 glasses at two depths: near the surface $(25 \mu \mathrm{m})$ and deeper in the bulk $(55 \mu \mathrm{m})$. The data fits are shown in Fig. 5, and a graphical representation of the obtained CNs and bond distances is displayed in Fig. 6 . A CN between 4 and 6 was found for $\mathrm{Fe}$ at the surface of the glasses, showing a fluctuation as a function of glass composition. This is in full agreement with the XANES pre-edge peak results. Generally, a higher $\mathrm{CN}$ is found for Fe at the surface, which is also confirmed by the XANES data (Fig. 4). Additionally, a change in $\mathrm{Fe}-\mathrm{O}$ bond distance at the surface of the glasses as a function of glass composition can be seen, with shorter bonds at higher $\left[\mathrm{Al}_{2} \mathrm{O}_{3}\right] /$ $\left[\mathrm{SiO}_{2}\right]$ ratio. Deeper in the glass sample (55 $\mu \mathrm{m}$ depth), the $\mathrm{Fe}-\mathrm{O}$ bond distance is found to be independent of $\left[\mathrm{Al}_{2} \mathrm{O}_{3}\right] /\left[\mathrm{SiO}_{2}\right]$ ratio.

Mysen et al. reported that an increase in $\mathrm{Fe}^{3+} / \sum \mathrm{Fe}$ results in an overall decrease in $\mathrm{CN}$ of Fe in glasses. ${ }^{39}$ Here, a decrease in $\mathrm{CN}$ and oxidation state with increasing $\mathrm{Al}_{2} \mathrm{O}_{3}$ content was perceived, suggesting an opposite trend to what was reported by Mysen et al. It should however be noted that the glasses discussed here were ion-exchanged, resulting in a compressive
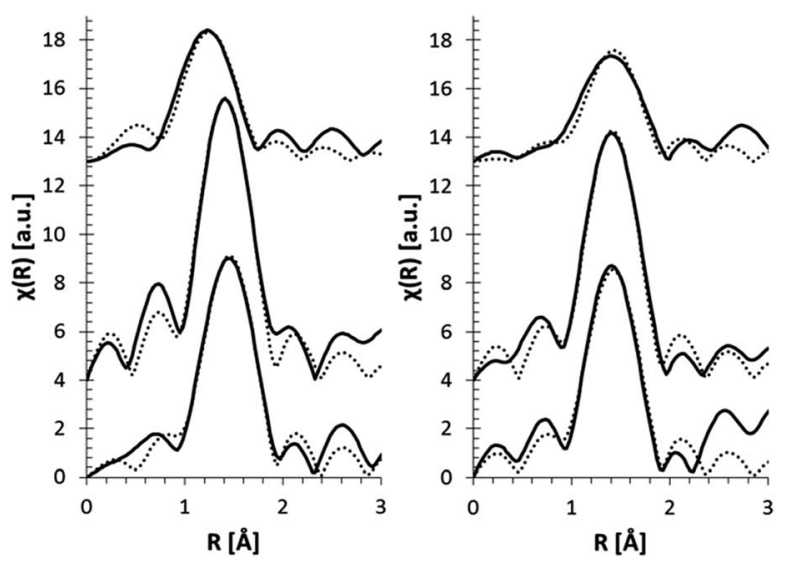

Fig. 5 EXAFS pseudo radial distribution magnitude plots (solid curve) and their fits (dotted curve) for glasses at $25 \mu \mathrm{m}$ (left) and $55 \mu \mathrm{m}$ depth (right). 


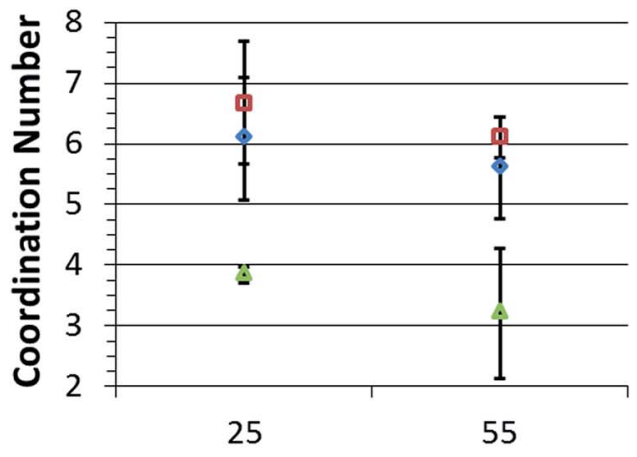

Sample depth $[\mu \mathrm{m}]$

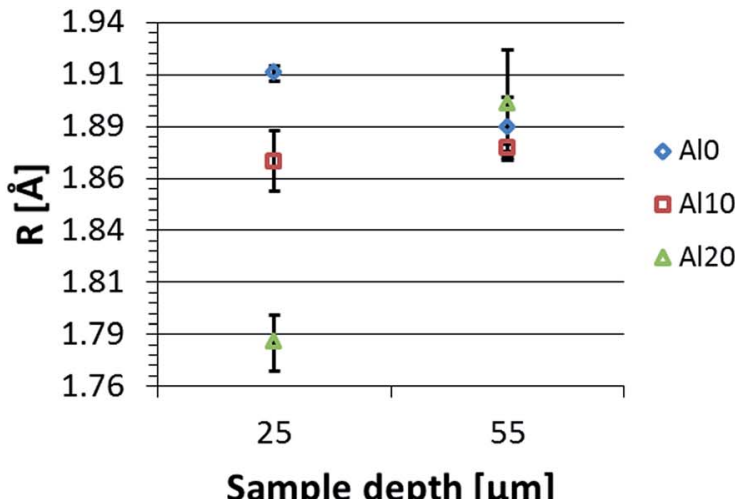

Fig. 6 EXAFS fitting results for multiple glasses at two different depths. The fitted coordination number (left) and nearest neighbour Fe-O scatter path length (right) are displayed.

stress of the surface layers. This compressive stress typically increases with $\left[\mathrm{Al}_{2} \mathrm{O}_{3}\right] /\left[\mathrm{SiO}_{2}\right] \mathrm{ratio}^{40}$ and may potentially lead to differences in $\mathrm{CN}$ for the different glasses. The change in oxidation state with glass composition on the other hand can be explained as a result of the differences in homogenization temperature for glasses with different $\mathrm{Al}_{2} \mathrm{O}_{3} / \mathrm{SiO}_{2}$ ratios, as was suggested in Smedskjaer et al. ${ }^{17}$

The decrease in $\mathrm{CN}$ and the increase of the $\mathrm{Fe}-\mathrm{O}$ bond distances with increasing sample depth can be understood by considering the effect of the IX process on the local atomic structure. Closer to the surface more Na atoms will have been replaced by the larger $\mathrm{K}$ atoms, resulting in a compression of the surface layers. As the surface layers are compressed, the bond distances will decrease and even the arrangement of $O$ atoms around $\mathrm{Fe}$ can change to a more tightly packed structure, increasing the $\mathrm{Fe} \mathrm{CN}$. Deeper in the sample less $\mathrm{Na}$ atoms will have been replaced due to the limited diffusion depth of the $\mathrm{K}$ atoms and a lower stress is observed, resulting in a less pronounced decrease in bond length or increase of $\mathrm{CN}$. This suggests that high compressive stress plays a similar role as high pressure in the glasses.

\section{Conclusions}

Fe-K edge confocal micro-XANES and -EXAFS experiments have been performed to study the Fe oxidation state and coordination number $(\mathrm{CN})$ as a function of depth and glass composition in a series of ion-exchanged (IX) boroaluminosilicate glasses in order to determine the structural and chemical differences of the Fe environment as a function of depth below the surface. It was found that XANES experiments are sufficient to obtain information on the oxidation state of transition metals (e.g., Fe) in these glasses, thus decreasing the exposure of the sample to radiation. In order to obtain quantitative information on the CN, EXAFS experiments are more conclusive.

The Fe oxidation state decreases with increasing $\left[\mathrm{Al}_{2} \mathrm{O}_{3}\right] /$ $\left[\mathrm{SiO}_{2}\right]$ ratio in the bulk of the glasses. This feature is believed to originate from the different homogenization temperatures applied to the different glasses. Also a decrease in $\mathrm{CN}$ was observed with increased alumina content. Additionally, the depth-resolved data show an increase of $\mathrm{CN}$ and decrease of Fe$\mathrm{O}$ bond distance at the surface compared to deeper inside the glass matrix, which is also explained by the IX process induced stress.

These findings represent previously unknown information on the impact of the IX-generated compressive stress and K-for$\mathrm{Na}$ substitution on the local atomic structure and will aid in further development and improvement of the unique characteristics and functionalities of such damage-resistant glasses. Moreover, it is shown that confocal micro-XAS experiments are a useful addition to analytical research in order to obtain unique information on a large variation of samples, not excluding in situ or similarly challenging experiments.

\section{Author contributions}

The manuscript was written through contributions of all authors. All authors have given approval to the final version of the manuscript.

\section{Acknowledgements}

We would like to thank Corning Inc. for providing us the samples to perform this study. P. Tack is funded by a Ph.D. grant of the Agency for Innovation by Science and Technology (IWT). M. Potuzak is gratefully acknowledged for suggesting this research. The Netherlands Organization for Scientific Research (NWO) and the Flanders Research Foundation (FWO) are acknowledged for providing access to the facilities of the DUBBLE beamlines at the ESRF.

\section{Notes and references}

1 S. R. Elliott, Physics of Amorphous Materials, Wiley, New York, 1988.

2 M. Guthrie, C. Tulk, C. Benmore, J. Xu, J. Yarger, D. Klug, J. Tse, H. K. Mao and R. Hemley, Phys. Rev. Lett., 2004, 93, DOI: 10.1103/PhysRevLett.93.115502. 
3 Y. Meng, H. K. Mao, P. J. Eng, T. P. Trainor, M. Newville, M. Y. Hu, C. Kao, J. Shu, D. Hausermann and R. J. Hemley, Nat. Mater., 2004, 3, 111-114.

4 J. L. Yarger, K. H. Smith, R. A. Nieman, J. Diefenbacher, G. H. Wolf, B. T. Poe and P. F. Mcmillan, Science, 1995, 270, 1964-1967.

5 M. Grimsditch, A. Polian and A. C. Wright, Phys. Rev. B: Condens. Matter Mater. Phys., 1996, 54, 152-155.

6 S. K. Lee, P. J. Eng, H.-K. Mao, Y. Meng, M. Newville, M. Y. Hu and J. Shu, Nat. Mater., 2005, 4, 851-854.

7 L. Wondraczek, S. Sen, H. Behrens and R. E. Youngman, Phys. Rev. B: Condens. Matter Mater. Phys., 2007, 76, DOI: 10.1103/PhysRevB.76.014202.

8 J. Wu, J. Deubener, J. F. Stebbins, L. Grygarova, H. Behrens, L. Wondraczek and Y. Yue, J. Chem. Phys., 2009, 131, 104504.

9 V. Tyagi and A. K. Varshneya, J. Non-Cryst. Solids, 1998, 238, 186-192.

10 A. K. Varshneya, J. Non-Cryst. Solids, 1975, 19, 355-365.

11 A. Tandia, K. D. Vargheese and J. C. Mauro, J. Non-Cryst. Solids, 2012, 358, 1569-1574.

12 A. Tandia, K. D. Vargheese, J. C. Mauro and A. K. Varshneya, J. Non-Cryst. Solids, 2012, 358, 316-320.

13 K. D. Vargheese, A. Tandia and J. C. Mauro, J. Non-Cryst. Solids, 2014, 403, 107-112.

14 D. C. Boyd, US Pat., US 3778335 A, 1973.

15 B. O. Myson, F. Seifert and D. Virgo, Am. Mineral., 1980, 65, 867-884.

16 M. M. Smedskjaer, J. C. Mauro and Y. Yue, J. Chem. Phys., 2009, 131, 244514.

17 M. M. Smedskjaer, Q. Zheng, J. C. Mauro, M. Potuzak, S. Mørup and Y. Yue, J. Non-Cryst. Solids, 2011, 357, 37443750.

18 Y. Xiang, J. Du, M. M. Smedskjaer and J. C. Mauro, J. Chem. Phys., 2013, 139, 044507.

19 Q. J. Zheng, R. E. Youngman, C. L. Hogue, J. C. Mauro, M. Potuzak, M. M. Smedskjaer and Y. Z. Yue, Phys. Rev. B: Condens. Matter Mater. Phys., 2012, 86, DOI: 10.1103/ PhysRevB.86.054203.

20 F. Farges, S. Rossano, Y. Lefrere, M. Wilke and G. E. Brown, Phys. Scr., 2005, 115, 957-959.

21 M. Wilke, G. M. Partzsch, R. Bernhardt and D. Lattard, Chem. Geol., 2005, 220, 141-161.

22 G. Giuli, S. G. Eeckhout, E. Paris, C. Koeberl and G. Pratesi, Meteorit. Planet. Sci., 2005, 40, 1575-1580.
23 A. J. Berry, H. S. O'Neill, K. D. Jayasuriya, S. J. Campbell and G. J. Foran, Am. Mineral., 2003, 88, 967-977.

24 E. Cottrell, K. A. Kelley, A. Lanzirotti and R. A. Fischer, Chem. Geol., 2009, 268, 167-179.

25 L. Galoisy, G. Calas and M. A. Arrio, Chem. Geol., 2001, 174, 307-319.

26 W. E. Jackson, F. Farges, M. Yeager, P. A. Mabrouk, S. Rossano, G. A. Waychunas, E. I. Solomon and G. E. Brown, Geochim. Cosmochim. Acta, 2005, 69, 4315-4332.

27 S. Fuhrmann, D. Schumacher, J. Herbst and L. Wondraczek, J. Non-Cryst. Solids, 2014, 401, 82-86.

28 P. Gonçalves Ferreira, D. de Ligny, O. Lazzari, A. Jean, O. Cintora Gonzalez and D. R. Neuville, Chem. Geol., 2013, 346, 106-112.

29 V. Martis, S. Nikitenko, S. Sen, G. Sankar, W. van Beek, Y. Filinchuk, I. Snigireva and W. Bras, Cryst. Growth Des., 2011, 11, 2858-2865.

30 H. B. Stanley, D. Banerjee, L. van Breemen, J. Ciston, C. H. Liebscher, V. Martis, D. H. Merino, A. Longo, P. Pattison, G. W. M. Peters, G. Portale, S. Sen and W. Bras, CrystEngComm, 2014, 16, 9331-9339.

31 S. Nikitenko, A. M. Beale, A. M. van der Eerden, S. D. Jacques, O. Leynaud, M. G. O'Brien, D. Detollenaere, R. Kaptein, B. M. Weckhuysen and W. Bras, J. Synchrotron Radiat., 2008, 15, 632-640.

32 G. Silversmit, B. Vekemans, S. Nikitenko, W. Bras, V. Czhech, G. Zaray, I. Szaloki and L. Vincze, J. Synchrotron Radiat., 2009, 16, 237-246.

33 G. Silversmit, B. Vekemans, S. Nikitenko, S. Schmitz, T. Schoonjans, F. E. Brenker and L. Vincze, Phys. Chem. Chem. Phys., 2010, 12, 5653-5659.

34 G. Silversmit, B. Vekemans, S. Nikitenko, K. Tirez, W. Bras, F. E. Brenker and L. Vincze, presented in part at the 14th International Conference on X-Ray Absorption Fine Structure (XAFS14), 2009.

35 S. Calvin, XAFS for Everyone, Taylor \& Francis, 2013.

36 K. V. Klementev, J. Phys. D: Appl. Phys., 2001, 34, 2241-2247. 37 A. L. Ankudinov, PhD thesis, University of Washington, 1996.

38 A. L. Ankudinov and J. J. Rehr, Phys. Rev. B: Condens. Matter Mater. Phys., 1997, 56, R1712-R1715.

39 B. O. Mysen, Geochim. Cosmochim. Acta, 2006, 70, 2337-2353. 40 M. J. Dejneka, J. C. Mauro, M. Potuzak, M. M. Smedskjaer, and R. E. Youngman, US Pat., US 9,145,333 B1, 2015. 